\title{
White coat bullies
}

1 young scientist puts in long hours at a lab for two years, working diligently, producing a large body of valuable data. When his supervisor publishes a paper based on the work in a high-profile journal, the young scientist's name is nowhere to be found.

A PhD student learns she will be joining a "dream" project in a subject area related to her research interests. She is shouted down at meetings, belittled in front of peers, excluded from publications and ignored during coffee breaks.

These are but two of many stories, most expressed anonymously, on a website devoted to bullying in research and academia. Though bullying is typically associated with schoolyards and high-pressure corporate settings, it is also a problem in institutes of higher learning, particularly those that invest heavily in research.

"Institutions that are the most research-intensive are likely to have more competitive cultures," says Jaime Lester, associate professor of higher education at George Mason University in Fairfax, Virginia. "In competitive cultures, you are more likely to see bullying incidences."

Researchers in some disciplines, including science and medicine, face many pressures. There is enormous competition for grants and positions at universities. Securing tenure can be a challenge, and the pressure to publish to advance one's career is ever-present.

Academics are also very skilled in analysis, critique and argumentation. In a hyper-competitive environment, these skills can be put to malicious use, to put others down for personal gain. This might be passed off as normal behaviour in the research world, considered professional criticism or character building, but it can sometimes tip over into bullying.

"If you stand back and look at the structure of research, it is wide open for bullying," says Frank Gannon, director and CEO of the QIMR Berghofer Medical Research Institute in Australia. "What are the checks and balances to prevent it? There are very few."

Bullying is a pervasive problem in research, Gannon once suggested in an editorial, though "scientists seem to accept it without further comment or disapproval as through it were a normal part of life." $\mathrm{PhD}$ students are particularly prone to being victims of bullying, wrote Gannon.

Senior scientists hold tremendous power over junior researchers, possessing

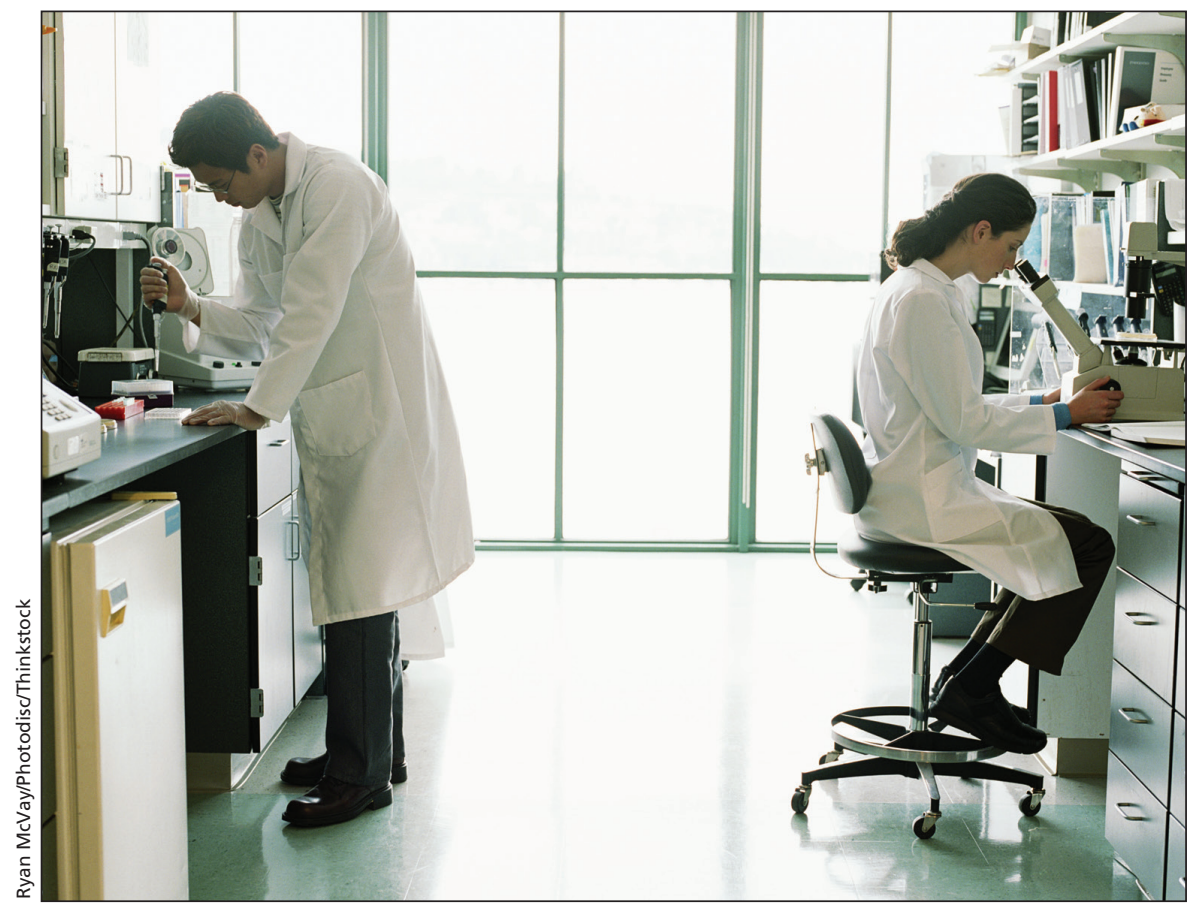

The competitive nature of science can make research environments prone to bullying rather than collaboration. the ability to advance or stall a career in its early stages. They can decide if $\mathrm{PhD}$ students receive proper credit for their work, if they can go to meetings and conferences and if they are assigned important tasks or grunt work. It is also highly unlikely, notes Gannon, that a junior researcher would point out flaws or weaknesses in their superiors' research.

"Here you have, effectively, an allpowerful employer," says Gannon. "The boss of the lab is all powerful."

If that boss also happens to be a bully, it can be a difficult problem to address. "If you have a high-powered researcher — a productive, successful faculty star - and yet they are behaving in an inappropriate way, whether not giving credit to their postdocs for their work or participating in bullying behaviour, it's difficult for human resources to have any recourse to address that, because it is not illegal," says Lester, who edited a book called Workplace Bullying in Higher Education.

Bullying is also subjective, open to interpretation. People labelled as bullies rarely self-identify in the role, believing their behaviour to be perfectly acceptable. And some use the term too liberally, calling someone a bully after a single unpleasant incident. According to Lester, however, there has to be a pattern - frequent incidents over an extended period, often increasing in intensity.

"I don't much like talking about bullying, especially because the term has come to be thrown around so loosely," Kenneth Westhues, professor emeritus of sociology and legal studies at the University of Waterloo in Ontario, writes in an email.

To better make sense of workplace conflicts, and to better address them, it is important to be more specific, says Westhues, the foremost expert on "mobbing," which he described in an essay as occurring when a number of ordinary workers at whatever level "unfairly gang up on a manager, peer, or subordinate."

"What we need is incisive, empirically sound analyses of why rotten things happen at work, analyses that point to effective means of prevention and remedy." - Roger Collier, CMAJ

CMAJ 2014. DOI:10.1503/cmaj.109-4808 